\title{
Seroprevalence of Cytomegalovirus Antibodies in a Group of Bangladeshi Women in Child-Bearing Age: A Pilot Study
}

\author{
Tasmi Tamanna $^{1 \sharp}$, Tania Mannan ${ }^{1,2 \sharp}$, Sa'dia Tasnim $^{1}$, Sharmina Yeasmin ${ }^{3}$, Rummana Mazid ${ }^{4}$ and Rosy Sultana ${ }^{{ }^{*}}$ \\ ${ }^{1}$ Department of Immunology, Bangladesh University of Health Sciences (BUHS), Mirpur, Dhaka-1216, Bangladesh \\ ${ }^{2}$ Department of Biochemistry and Molecular Biology, Bangladesh University of Health Sciences (BUHS), Mirpur, Dhaka-1216, Bangladesh \\ ${ }^{3}$ Department of Gynaecology and Obstetrics, Bangladesh Institute of Health Sciences General Hospital (BIHSGH), Mirpur, Dhaka-1216, Bangladesh \\ ${ }^{4}$ Department of Microbiology, Bangladesh Institute of Health Sciences General Hospital (BIHSGH), Mirpur, Dhaka-1216, Bangladesh \\ "Joint-first authorship
}

${ }^{\star}$ Corresponding author: Rosy Sultana, Department of Immunology, Bangladesh University of Health Sciences (BUHS), Mirpur, Dhaka-1216, Bangladesh

Received: April 09, 2021; Accepted: May 21, 2021; Published: June 01, 2021

\begin{abstract}
Background: Human Cytomegalovirus (HCMV) is the most common cause of congenital infections and can be life-threatening in immune compromised individuals. We aimed to shed light on the Seroprevalence of HCMV antibodies in women of child-bearing age in a tertiary care hospital and in a health science university of Bangladesh.
\end{abstract}

Methods: A total of 84 apparently healthy 20-40 years old women (42 pregnant and 42 non-pregnant) were screened for anti-CMV IgG and IgM antibodies using Enzyme Linked Immunosorbent Assay (ELISA). Serum levels of bilirubin, and liver enzymes (alanine aminotransferase, aspartate aminotransferase) were evaluated by biochemistry auto analyzers.

Results: All the participants were found positive for anti-CMV IgG (100\%) while 1 pregnant woman revealed positivity for both IgM and IgG justifying recent infection. CMV IgG antibody was found positive in $48(68.6 \%)$ and $14(100 \%)$ relatively younger volunteers in married (n=70) and unmarried $(n=14)$ group respectively, and in $22(31.4 \%)$ elderly volunteers of married group. Significantly higher mean value of Sample Optical Density (SOD) for CMV IgM was observed in pregnant than that of non-pregnant counterpart ( $p=0.023 ; 95 \% \mathrm{CI}=0.032-0.002)$. Again, the mean SOD of CMV IgG was significantly lower in non-pregnant women compared to that of the pregnant women in the employed group [ $p=0.029 ; 95 \% \mathrm{CI}=1.176-(-0.006)]$.

Conclusion: The present study demonstrates that the women of child bearing age are very much exposed to CMV infection. Pregnancy and working outside (employment) are two important risk factors for repeated exposure to infection as indicated by higher measured Optical Density (OD) for CMV IgG. A comprehensive study with a long-term follow-up of offspring born to HCMV IgM-positive mothers would provide estimates of an accurate percentage of symptomatic congenital HCMV infection in Bangladesh.

Keywords: CMV IgM, CMV IgG antibody, ELISA, Child-bearing age

\section{Introduction}

Human Cytomegalovirus (CMV), a double-stranded DNA virus belonging to the Herpesviridae family, is widespread throughout the world. The seroprevalence rates of CMV vary in countries with an estimated seroprevalence of $45 \%$ to $100 \%$ in the general population [1-3]. Globally, the disease burden is highest because of congenital $\mathrm{CMV}$ infection. Non-primary maternal infection among seropositive women is the cause of most congenital infections in populations with high CMV seroprevalence [4] though there are potential risk factors also for pregnant seronegative women in these settings. Intrauterine transmission of this virus has been associated with both primary and non-primary maternal CMV infection resulting in birth defects and long-term developmental disabilities [4]. Permanent sequelae include Sensorineural Hearing Loss (SNHL), microcephaly, seizures, neurologic deficits, and retinitis. The virus becomes latent after primary infection and sporadic recurrence with intermittent viral shedding may last throughout the life an important source of infection [5]. Studies in high-income and middle-income countries revealed that sensorineural hearing loss and neurological damage due to CMV infection is driven by maternal infection that occurs before 14 weeks of pregnancy [6,7]. Majority of the patients are asymptomatic but can cause life-threatening complications in immunocompromised individuals like patients with AIDS and other immune disorders, transplant recipients, individuals admitted to intensive-care units, and to some extent in elderly people [8]. In these patients, high viral loads in the urine are associated with viraemia, dissemination to multiple organs, and end-organ diseases such as pneumonitis, retinitis, hepatitis, or gastroenteritis [9]. Transmission of CMV via blood transfusion and blood component is a matter for concern among blood bank professionals and blood transfusion recipient, particularly in cases of transfusion to neonates and immunocompromised patients. 
Few women are aware of this public health burden [10-12] which can be alleviated by widespread education relating CMV transmission and preventive hygiene behavior and thereby can reduce congenital CMV infections [13-17]. Active and passive immunization strategies would be necessary to prevent in utero infection. The tendency for infection with multiple different virus strains and high virus diversity pose a vital biological barrier to the progress of effective vaccines [18-22]. Though there is no licensed vaccine available so far that protects against CMV, still several vaccine candidates are being tested now in clinical trials [23-25]. To address public health issue and for primary prevention through immunization, epidemiological data on CMV susceptibility of the population are crucial so that undesirable consequences in infants could be circumvented. Since there is insufficient population-based CMV-specific IgG seroprevalence data available for adults of Bangladesh, the aims of this study were to estimate CMV seroprevalence in the women of child bearing age in Bangladesh and to identify socio-demographic factors that are potentially associated with CMV seropositivity.

\section{Methods and Materials}

\section{Study Design, Setting, and Type of Participants/Materials Involved}

This cross-sectional study spanned between July 2019 to June 2020 which included total 84 (42 pregnant, 42 non-pregnant) women. Pregnant women of child-bearing age (20-40 years) attending at the Obstetrics and Gynaecology out-patient department of Bangladesh Institute of Health Sciences General Hospital, Mirpur, Dhaka for routine antenatal checkup and non-pregnant women (faculty members, staffs and senior students) of equal age group from the Bangladesh University of Health Sciences (BUHS) were enrolled as study subjects. Pregnancy status and duration of pregnancy was confirmed by Obstetricians diagnosis and ultrasonography report (USG of lower abdomen) respectively.

\section{Specimen Collection and Serum Preparation}

Under aseptic precaution, $4 \mathrm{ml}$ of blood sample was collected from each volunteer by venipuncture and transferred to a vacutainer (plain red-top tube). Prior to sample collection, a written informed consent was obtained from each participant. Sample was allowed to stand for one hour to clot and then centrifuged at $3000 \mathrm{rpm}$ for 15 minutes. Separated serum was aliquoted into three microcentrifuge tubes $(0.5$ $\mathrm{ml}$ in each). One aliquot was used for biochemical liver function test, another for determination of IgM and IgG antibodies for CMV. The third aliquot was preserved at $-20^{\circ} \mathrm{C}$ for future laboratory analyses (if any).

\section{Liver Function Test, Anti-CMV IgM and Anti-CMV IgG Detection}

Liver function tests; serum bilirubin, ALT (Alanine Transaminase) and AST (Aspartate Transaminase) levels were estimated by biochemistry auto analyzer (Dimension, Siemens, Germany). AntiCMV IgM and anti-CMV IgG antibodies were determined by Enzyme Linked Immunosorbent Assay (ELISA) method using commercially available qualitative ELISA kits (DRG, Germany).

\section{Statistical Analysis}

Data were expressed as mean $\pm \mathrm{SD}$, number (percent) as appropriate. Statistical Package for Social Sciences (SPSS Inc., Chicago, IL, USA) version 20.0 was used to carry out statistical analysis. Unpaired Student's ' $\mathrm{t}$ '-test and Chi-squared test with $95 \%$ Confidence Interval (CI) were applied to calculate statistical difference and association for continuous and qualitative data respectively. Means and standard deviations were calculated for continuous variables while frequencies and percentages were calculated for categorical variables. Data were presented by tables and figures. A p value of less than 0.05 was considered as level of significance.

\section{Ethical Aspects}

The study was carried out following the international codes for ethical use of human subjects. The study was approved by the Ethical Review Committee (ERC) of Bangladesh University of Health Sciences and proper ethical guidelines were followed during sample collection.

To meet the ethical consideration an information sheet explaining the purpose of the study was provided to the subjects and a written informed consent from each of the participants was sought to recruit them in this study.

\section{Results}

Socio economic characteristics of the volunteers were shown in Table 1. The study included adult women (pregnant 42 and nonpregnant 42) of child bearing age in Dhaka city of age range from 20 to 40 years. Mean ( \pm SD) age (years) of the pregnant cases was $27.62( \pm$ 4.57 ) and non-pregnant 28.21 ( \pm 5.41$)$. Most of the participants (67\%) of the pregnant women group were homemakers and rests involved in job of different type (33\%). Of the non-pregnant counterpart majority (67\%) were working outside which demonstrated statistically significant association $(\mathrm{p}=0.002)$.

All the participants were found to be seropositive for CMV IgG antibody irrespective of pregnancy status, whereas only one pregnant woman of 28 years was found to be seropositive for CMV IgM antibody at her third trimester of pregnancy.

CMV IgG antibody was found positive in $48(68.6 \%)$ and 14 $(100 \%)$ relatively younger volunteers in married $(n=70)$ and unmarried

Table 1: Socio-economic characteristics in respect to the pregnancy status ( $\mathrm{N}=84$ ).

\begin{tabular}{|c|c|c|c|c|c|}
\hline \multicolumn{2}{|c|}{ Variables } & $\begin{array}{c}\text { Pregnant } \\
(n=42) \text { N (\%) }\end{array}$ & $\begin{array}{c}\text { Non-pregnant } \\
(\mathrm{n}=42) \mathrm{N}(\%)\end{array}$ & $x^{2}$ & $p$ value \\
\hline \multirow{2}{*}{$\begin{array}{l}\text { Educational } \\
\text { Level }\end{array}$} & Upto class 12 & $12(38)$ & $20(62)$ & \multirow{2}{*}{3.23} & \multirow{2}{*}{0.072} \\
\hline & Graduate and Higher & $30(58)$ & $22(42)$ & & \\
\hline \multirow{2}{*}{$\begin{array}{l}\text { Occupational } \\
\text { Status }\end{array}$} & Employed & $14(33)$ & $28(67)$ & \multirow{2}{*}{9.33} & \multirow{2}{*}{0.002} \\
\hline & Unemployed & $28(67)$ & $14(33)$ & & \\
\hline \multirow{2}{*}{ Income group } & Below cut off & $30(52)$ & $28(48)$ & \multirow{2}{*}{0.223} & \multirow{2}{*}{0.637} \\
\hline & Above cut off & $12(46)$ & $14(54)$ & & \\
\hline
\end{tabular}

Results were expressed as number and percentage. Chi square test was performed to calculate significant statistical association. $\mathrm{p}<0.05$ was considered as level of statistical significance.

Income group taking per-capita income USD 2064/- to date; Unemployed include homemakers ( 26 pregnant $\& 5$ non pregnant) and students ( 2 pregnant $\& 9$ non pregnant). 
$(\mathrm{n}=14)$ group respectively, and in $22(31.4 \%)$ elderly volunteers of married group (Figure 1).

Mean \pm SD of Age, Bilirubin, ALT and AST levels in pregnant and non-pregnant group did not show any statistically significant difference (Table 2). It was observed that majority of the subjects had no history of blood transfusion and jaundice (pregnant $83.3 \%$ and $95.2 \%$ respectively and non-pregnant women $90.5 \%$ and $90.5 \%$ respectively). It was also found that majority of the pregnant women (83.3\%) had no history of major surgery previously. Although $69 \%$ of non-pregnant women had no history of major surgery in their previous days, almost one-third (31\%) of this group had positive history of major surgery previously (Data not shown).

When we measured Optical Density (OD) for CMV IgM, it was observed significantly higher in pregnant than that in the nonpregnant women $(\mathrm{p}=0.023)$. No such significant difference was seen in case of CMV IgG (Table 3).

Upon comparison between employed and unemployed status, the OD for measurement of CMV IgG was significantly higher in pregnant women than that of the non-pregnant women in the employed group ( $\mathrm{p}=0.029)$. Among the unemployed group, it is quite similar $(2.57 \pm 1.22$ in pregnant and $2.49 \pm 0.75$ in non-pregnant $)$ $(\mathrm{p}=0.184)$. No statistically significant difference was observed in OD for measurement of CMV IgM (Table 4).

\section{Discussion}

All the subjects of childbearing age (20-40 years), pregnant and non-pregnant, recruited in the study demonstrated $100 \%$ seropositivity

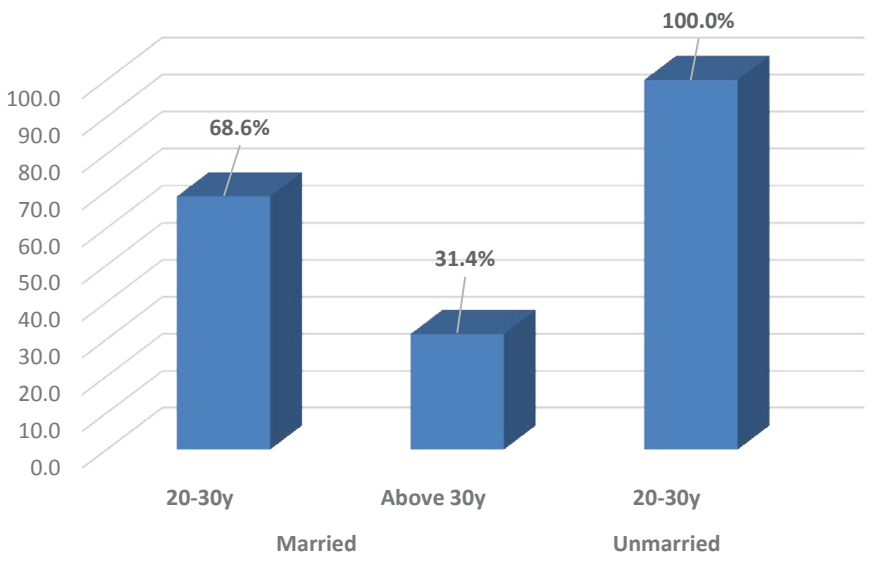

Figure 1: Percentage of positive CMV IgG antibody among different age group of married and unmarried women.

Table 2: Age and biochemical variables of the subjects in respect to Pregnancy status ( $\mathrm{N}=84$ ).

\begin{tabular}{|l|c|c|c|c|c|}
\hline \multirow{2}{*}{ Variables } & \multirow{2}{*}{$\begin{array}{c}\text { Pregnant } \\
(\mathbf{n = 4 2})\end{array}$} & \multirow{2}{*}{$\begin{array}{c}\text { Non-pregnant } \\
(\mathbf{n = 4 2})\end{array}$} & \multirow{2}{*}{ p value } & \multicolumn{2}{|c|}{ 95\% CI } \\
\cline { 5 - 7 } & & & Upper & Lower \\
\hline Age (yrs) & $27.62 \pm 4.57$ & $28.21 \pm 5.41$ & 0.59 & 1.58 & -2.78 \\
\hline S bilirubin (mg/dl) & $0.31 \pm 0.13$ & $0.37 \pm 0.17$ & 0.07 & -0.13 & 0.01 \\
\hline S ALT (U/l) & $22.63 \pm 8.51$ & $22.41 \pm 6.82$ & 0.89 & 3.56 & -3.13 \\
\hline S AST (U/l) & $23.78 \pm 12.19$ & $20.67 \pm 5.43$ & 0.14 & 7.2 & -0.99 \\
\hline
\end{tabular}

Results were expressed as Mean \pm SD. Unpaired Students' t-test was performed to calculate statistical difference between the two groups. $p<0.05$ was considered significant.
Table 3: Mean values of optical density (OD) of CMV IgG and CMV IgM with Pregnancy status $(\mathrm{N}=84)$.

\begin{tabular}{|l|c|c|c|c|c|}
\hline \multirow{2}{*}{$\begin{array}{l}\text { Optical density } \\
(\mathbf{O D})\end{array}$} & \multirow{2}{*}{$\begin{array}{c}\text { Pregnant } \\
(\mathbf{n = 4 2})\end{array}$} & \multirow{2}{*}{$\begin{array}{c}\text { Non pregnant } \\
(\mathbf{n = 4 2})\end{array}$} & \multirow{2}{*}{ P value } & \multicolumn{2}{|c|}{ 95\% CI } \\
\cline { 5 - 7 } & & & & Upper & Lower \\
\hline CMV IgG & $2.78 \pm 1.08$ & $2.70 \pm 0.73$ & 0.711 & 0.477 & 0.327 \\
\hline CMV IgM & $0.040 \pm 0.044$ & $0.023 \pm 0.17$ & 0.023 & 0.032 & 0.002 \\
\hline
\end{tabular}

Results were expressed as Mean \pm SD. Unpaired Students' t-test was performed to calculate statistical difference between the two groups. $p<0.05$ was considered significant.

Table 4: Optical density values of CMV IgG and IgM assay among those employed and unemployed of pregnant and non-pregnant subjects $(\mathrm{N}=84)$.

\begin{tabular}{|l|l|l|l|l|l|l|}
\hline \multirow{2}{*}{ Variable } & \multirow{2}{*}{ Pregnant $(\mathbf{n}=42)$} & \multicolumn{2}{|c|}{ Non pregnant $(\mathbf{n = 4 2 )}$} & \multirow{2}{*}{ P value } & \multicolumn{2}{|c|}{$\mathbf{9 5 \%}$ CI } \\
\cline { 6 - 8 } & & & & Upper & Lower \\
\hline \multirow{2}{*}{$\begin{array}{l}\text { CMV IgG } \\
\text { assay }\end{array}$} & Employed (14/28) & $3.19 \pm 0.55$ & $2.81 \pm 0.71$ & 0.029 & 1.176 & -0.066 \\
\cline { 6 - 8 } & Unemployed (28/14) & $2.57 \pm 1.22$ & $2.49 \pm 0.75$ & 0.184 & 0.799 & -0.158 \\
\hline \multirow{2}{*}{$\begin{array}{l}\text { CMV IgM } \\
\text { assay }\end{array}$} & Employed (14/28) & $0.043 \pm 0.07$ & $0.020 \pm 0.01$ & 0.817 & 0.033 & -0.026 \\
\cline { 6 - 8 } & Unemployed (28/14) & $0.039 \pm 0.03$ & $0.029 \pm 0.02$ & 0.098 & 0.001 & 0.02 \\
\hline
\end{tabular}

Results were expressed as Mean \pm SD. Unpaired Students' t-test was performed to calculate statistical difference between the two groups. $p<0.05$ was considered significant.

for anti-CMV IgG antibody. It suggests that these women had been exposed with cytomegalovirus previously at some points of their life. They were of different occupations ranging from being unemployed housewives to pursuing high careers and also students. The level of education also ranged widely up to post-graduation. This vast diversity of participants being positive for CMV IgG represents that the virus is well spread through the population of Bangladesh. The present study is supported by report carried out in a tertiary care hospital of Dhaka which also demonstrated $100 \%$ pregnant women were seropositive for anti CMV IgG antibody in their first antenatal visit, reflecting a high seroprevalence of CMV IgG in Bangladesh [26]. Another recent study in Bangladesh revealed 91\% seroprevalence of CMV IgG among the blood donors [27]. Finding of this study is also consistent with a report from India where seropositivity of anti-CMV IgG was $87 \%$ in women of child bearing age [28]. Higher seroprevalence of CMV IgG in pregnant women was also found in other countries like $98.5 \%$ in Turkey [29], 89.6\% in Mexico [30] and 98\% in Brazil [31]. A systematic review and meta-analysis estimated global mean seroprevalence for the general population was $83 \%$ and the maximum mean seroprevalence was found $90 \%$ in the Eastern Mediterranean region, while the lowest was $66 \%$ in the European countries [1].

Majority of the participants from both pregnant and non-pregnant group in this study had no previous history of blood transfusion and never underwent a major surgery although it is proven that CMV infection is not directly related with blood transfusion which can be justified by a study where CMV DNA was rarely identified in healthy blood donors validated by Polymerase Chain Reaction (PCR) assay [32]. Most of the subjects in our study never had jaundice.

One pregnant woman in her third trimester was found to be positive for both anti-CMV IgM and IgG antibodies. Being positive for both types of antibodies makes it impossible to determine whether it was a primary infection, a re-infection, or a super-added infection during the pregnancy. Although the low Sample Optical Density for IgM 
(SOD: 0.262) in comparison to that of IgG (SOD: 3.14) was indicative for convalescence stage of a primary infection earlier in her pregnancy or there may be a possibility of low level of re-infection. Our study does not correlate with findings of a hospital study in Dhaka where the researchers found $60 \%$ of the pregnant women were positive for antiCMV IgM antibody, whereas $1.3 \%$ newborns of CMV IgM positive mothers were also found positive for CMV IgM antibody [26]. We did not perform such screening in the newborns in our study. However, the CMV IgM positive mother in our study neither showed any symptom of viral infection nor had a suggestive history during blood collection. Again, her USG of pregnancy profile revealed a normal pregnancy going on. Since this pregnant woman was moderately anemic $(\mathrm{Hb}$ level: $9 \mathrm{gm} / \mathrm{dl}$, data not shown), it probably exposes her vulnerability to viral infections due to poor immune status though single finding is not enough to prove. Her serum Bilirubin, ALT and AST levels were all within normal range possibly for the mild infection. Since, anemia significantly correlated with pregnancy status, our findings did not support its relationship with CMV infection. Especially iron deficiency anemia affects humoral immunity adversely which subsequently renders increased chance of viral infection. Although high incidence of anemia in pregnancy is probably the result of inadequate intake of nutritious food and increasing demand for iron and folic acid making them more vulnerable to different viral infections [33]. CMV has an uncommon link with anemia since it is one of the features of Chronic Kidney Disease (CKD) and a complication of renal transplantation because of impaired production of erythropoietin [34].

Both married and unmarried participants who were relatively younger (20-30 years) showed increased seropositivity for CMV IgG than the older (above 30 years) age group. A longitudinal study in Germany also exhibited the maximum seroprevalence in the 16-20 years age group [35].

Significantly, higher mean SOD value of CMV IgM in pregnant women compared to non-pregnant women reflects probable reactivation of the virus since CMV IgM is highly sensitive but has poor specificity for identifying primary CMV infection. One drawback of this study was that we could not measure Avidity Index (AI) which is a suitable diagnostic tool for the detection of primary infection or reactivation/reinfection. Low CMV IgG avidity indicates primary infection whereas high avidity exhibits past infection or reactivation excluding primary infection [36-38].

Another limitation was the small sample size which was confined to only one selected hospital and health Science University at same premise. Newborns of infected mothers could not be screened for the presence of CMV antibodies due to time constraints.

In this study, we observed that the pregnant women who were employed, more likely to demonstrate significantly higher mean SOD value for CMV IgG than the employed but non-pregnant women. This higher measurement for CMV IgG assay perhaps may be caused by repeated exposure (for working outside) to the CMV infection during pregnancy or by development of cross-reactive antibodies in pregnant women. Higher prevalence of CMV IgG among working women was observed than homemakers though the difference was not significant demonstrated by Aljumaili et al., [39].
Moreover, immunocompromised state during pregnancy makes the women much more vulnerable to any kind of infection like infection by CMV.

A major strength of this study was the use of a representative population-based sample to determine CMV seroprevalence in women of reproductive age. But longitudinal analysis with large sample size and factors associated with it would be essential to figure out the true picture of CMV seroprevalence in women.

\section{Conclusion}

Data suggest that high endemicity of CMV infection is present in women of child bearing age in Bangladesh. To reduce the risk of $\mathrm{CMV}$ infection, measures like CMV screening during pregnancy and educating seronegative women could prevent congenital CMV infections with its serious consequences. Advanced laboratory techniques like PCR may be applied for strain detection and following up treatment outcome. Moreover, due to mutation, a strain of CMV is possible to emerge with devastating effects such as seen in case of COVID-19.

\section{Acknowledgement}

We are thankful as well as grateful to the BUHS authority for financial support to perform the study and to all the subjects who participated voluntarily in this study.

\section{References}

1. Zuhair M, Smit GSA, Wallis G, Jabbar F, Smith C, et al. (2019) Estimation of the worldwide seroprevalence of cytomegalovirus: A systematic review and metaanalysis. Rev Med Virol e2034. [crossref]

2. Lachmann R, Loenenbach A, Waterboer T, Brenner N, Pawlita M, et al. (2018) Cytomegalovirus (CMV) seroprevalence in the adult population of Germany. PLoS ONE 13: e0200267. [crossref]

3. Cannon MJ, Schmid DS, Hyde TB (2010) Review of cytomegalovirus seroprevalence and demographic characteristics associated with infection. Rev Med Virol 20: 202213. [crossref]

4. Manicklal S, Emery VC, Lazzarotto T, Boppana SB, Gupta RK (2013) The "silent" global burden of congenital cytomegalovirus. Clin Microbiol Rev 26: 86-102.

5. Cannon MJ, Stowell JD, Clark R, Dollard PR, Johnson D, et al. (2014) Repeated measures study of weekly and daily cytomegalovirus shedding patterns in saliva and urine of healthy cytomegalovirus-seropositive children. BMC Infect Dis 14: 569. [crossref]

6. Chatzakis C, Ville Y, Makrydimas G, Dinas K, Zavlanos A, et al. (2020) Timing of primary maternal cytomegalovirus infection and rates of vertical transmission and fetal consequences. Am J Obstet Gynecol 223: 870-883. [crossref]

7. Faure-Bardon V, Magny J-F, Parodi M, Couderc S, Garcia P, et al. (2019) Sequelae of congenital cytomegalovirus following maternal primary infections is limited to those acquired in the first trimester of pregnancy. Clin Infect Dis 69: 1526-1532. [crossref]

8. Griffiths PD (2012) Burden of disease associated with human cytomegalovirus and prospects for elimination by universal immunisation. Lancet Infect Dis 12: 790-798. [crossref]

9. Emery VC, Sabin CA, Cope AV, Gor D, Hassan-Walker AF, et al. (2000) Application of viral-load kinetics to identify patients who develop cytomegalovirus disease after transplantation. Lancet 355: 2032-2036. [crossref]

10. Willame A, Blanchard-Rohner G, Combescure C, Irion O, Posfay-Barbe $\mathrm{K}$, et al (2015) Awareness of Cytomegalovirus Infection among Pregnant Women in Geneva, Switzerland: A Cross sectional Study. Int J Environ Res Public Health 12: 15285-15297. [crossref]

11. Thackeray R, Magnusson BM (2016) Women's attitudes toward practicing cytomegalovirus prevention behaviors. Prev Med Rep 4: 517-524. [crossref] 
12. Binda S, Pellegrinelli L, Terraneo M, Caserini A, Primache V, et al. (2016) What people know about congenital CMV: an analysis of a large heterogeneous population through a web-based survey? BMC Infect Dis 16: 513.

13. Picone O, Vauloup-Fellous C, Cordier AG, Parent Du Chatelet I, Senat MV, et al. (2009) A 2-year study on cytomegalovirus infection during pregnancy in a French hospital. BJOG 116: 818-823. [crossref]

14. Reichman O, Miskin I, Sharoni L, Eldar-Geva T, Goldberg D, et al. (2014) Preconception screening for cytomegalovirus: an effective preventive approach. Biomed Res Int 2014: 135416.

15. Adler SP, Finney JW, Manganello AM, Best AM (2004) Prevention of child-tomother transmission of cytomegalovirus among pregnant women. J Pediatr 145: 485-491. [crossref]

16. Vauloup-Fellous C, Picone O, Cordier AG, Parent-du-Chatelet I, Senat MV, et al. (2009) Does hygiene counseling have an impact on the rate of CMV primary infection during pregnancy? Results of a 3-year prospective study in a French hospital. J Clin Virol 46: S49-53. [crossref]

17. Revello MG, Tibaldi C, Masuelli G, Frisina V, Sacchi A, et al. (2015) Prevention of Primary Cytomegalovirus Infection in Pregnancy. EBioMedicine 2: 1205-1210. [crossref]

18. Boppana SB, Rivera LB, Fowler KB, Mach M, Britt WJ (2001) Intrauterine transmission of cytomegalovirus to infants of women with preconceptional immunity. N Engl J Med 344: 1366-1371. [crossref]

19. Hansen SG, Powers CJ, Richards R, Ventura AB, Ford JC, et al. (2010) Evasion of CD8+T cells is critical for superinfection by cytomegalovirus. Science 328: 102-106. [crossref]

20. Pignatelli S, Dal Monte P, Rossini G, Landini MP (2004) Genetic polymorphisms among Human Cytomegalovirus (HCMV) wild-type strains. Rev Med Virol 14: 383410. [crossref]

21. Ross SA, Arora N, Novak Z, Fowler KB, Britt WJ, Boppana SB (2010) Cytomegalovirus reinfections in healthy seroimmune women. J Infect Dis 201: 386-389. [crossref]

22. Yamamoto AY, Mussi-Pinhata MM, Boppana SB, Novak Z, Wagatsuma VM, et al. (2010) Human cytomegalovirus reinfection is associated with intrauterine transmission in a highly cytomegalovirus-immune maternal population. Am J Obstet Gynecol 202: 297.e291-298. [crossref]

23. Smith LR, Wloch MK, Chaplin JA, Gerber M, Rolland AP (2013) Clinical Development of a Cytomegalovirus DNA Vaccine: From Product Concept to Pivotal Phase 3 Trial. Vaccines (Basel) 1: 398-414. [crossref]

24. Bernstein DI, Munoz FM, Callahan ST, Rupp R, Wootton SH, et al. (2016) Safety and efficacy of a cytomegalovirus glycoprotein $\mathrm{B}(\mathrm{gB})$ vaccine in adolescent girls: A randomized clinical trial. Vaccine 34: 313-319. [crossref]

25. Pass RF, Zhang C, Evans A, Simpson T, Andrews W, Huang ML, et al. (2009) Vaccine prevention of maternal cytomegalovirus infection. N Engl J Med 360: 1191-1199. [crossref]
26. Jahan M, Sultana N, Asma R, Tabassum S, Islam MN (2017) Birth Prevalence of Congenital Cytomegalovirus (CMV) infection in a cohort of pregnant women in Bangladesh. Bangladesh Med Res Counc Bull 43: 77-81.

27. Shaheen SSI, Hoque MA, Ferdous J (2020) Seroprevalence of Cytomegalovirus among Blood Donor in Transfusion Medicine: Study from Bangladesh. International Journal of Innovative Research in Medical Science 5.

28. Sheevani, Jindal N, Aggarwal A (2005) A pilot seroepidemiological study of cytomegalovirus infection in women of child bearing age. Ind J Med Microbiol 23: 34-36. [crossref]

29. Satilmiş A, Güra A, Ongun H, Mendilcioğlu I, Colak D, et al. (2007) CMV seroconversion in pregnants and the incidence of congenital CMV infection. Turk J Pediatr 49: 30-36. [crossref]

30. Esquivel CA, Terrones-Saldivar MC, Hernandez-Tinoco J, Munoz-Terrones MDE, Gallegos-Gonzalez RO, et al. (2018) Seroepidemiology of Cytomegalovirus Infection in Pregnant Women in the Central Mexican City of Aguascalientes. J Clin Med Res 10: 337-344. [crossref]

31. Mussi-Pinhata MM, Yamamoto AY, Aragon DC, Duarte G, Fowler KB, et al. (2018) Seroconversion for Cytomegalovirus Infection During Pregnancy and Fetal Infection in a Highly Seropositive Population: "The BraCHS Study". The Journal of Infectious Diseases 218: 1200-1204. [crossref]

32. Roback JD, Drew WL, Laycock ME, Todd D, Hillyer CD, et al. (2003) CMV DNA is rarely detected in healthy blood donors using validated PCR assays. Transfusion 43: 314-321. [crossref]

33. Hassan TH, Badr MA, Karam NA, Zkaria M, El Saadany HF, et al. (2016) Impact of iron deficiency anemia on the function of the immune system in children. Medicine 95. [crossref]

34. Butler LM, Dzabic M, Bakker F, Davoudi B, Jeffery H, et al. (2014) Human cytomegalovirus inhibits erythropoietin production. J Am Soc Nephrol 25: 16691678. [crossref]

35. Hoehl S, Berger A, Ciesek S and Rabenau HF (2020) Thirty years of CMV seroprevalence-a longitudinal analysis in a German university hospital. European Journal of Clinical Microbiology \& Infectious Diseases 39: 1095-1102.

36. Grangeot-Keros L, Mayaux MJ, Lebon P, Freymuth F, Eugene G, et al. (1997) Value of Cytomegalovirus (CMV) IgG avidity index for the diagnosis of primary CMV infection in pregnant women. J Infect Dis 175: 944-996. [crossref]

37. Bodeus M, Feyder S, Goubau P (1998) Avidity of IgG antibodies distinguishes primary from non-primary cytomegalovirus infection in pregnant women. Clin Diagn Virol 9: 9-16. [crossref]

38. Lazzarotto T, Spezzacatena P, Pradelli P, Abate DA, Varani S, et al. (1997) Avidity of immunoglobulin $\mathrm{G}$ directed against human cytomegalovirus during primary and secondary infections in immunocompetent and immunocompromised subjects. Clin Diagn Lab Immunol 4: 469-473. [crossref]

39. Aljumaili ZKM, Alsamarai AM, Najem WS (2014) Cytomegalovirus seroprevalence in womenwith bad obstetric history in Kirkuk, Iraq. Journal of Infection and Public Health 7: 277-288.

\section{Citation:}

Tamanna T, Mannan T, Tasnim S, Yeasmin S, Mazid R, et al. (2021) Seroprevalence of Cytomegalovirus Antibodies in a Group of Bangladeshi Women in Child-Bearing Age: A Pilot Study. ARCH Women Health Care Volume 4(3): 1-5. 